\title{
Teaching Cultural Strategies for Undergraduate Chinese-English Translation in Chinese Context
}

\author{
Chunying Lia, Shu-huai Wangb
}

\begin{abstract}
Although in China, ordinary translation theories favor the foreignizing strategy in translating culture, and outside China, there are opposing strategies between the cultural studies school and deconstructionist school, translation teachers should be fully aware of their respective revelations and limitations to translation teaching. This paper holds that in undergraduate C-E (Chinese-English) translation teaching, the linguistic strategy is assimilation rather than alienation, thus, idiomaticness and preciseness should be emphasized. In teaching cultural translation strategy, first, we should promote students' cultural competence, which includes culture perceptive competence, culture comparison competence, culture evaluation competence, and culture mediation competence. Second, we need differentiate cultural strategies to translate literary and practical materials. In translating practical materials, functionality determines adaptation or exoticization; in translating literary materials, when cultural factor is the topic of writing, exoticization is employed for the main except that part of politeness system in institutional culture, abstract concrete conversion and description affection model in spiritual culture are adapted. When cultural factor is the background of writing, it is the target text aestheticality and readership intertextuality that determine adaptation or exoticization.
\end{abstract}

\section{Keywords}

C-E (Chinese-English) translation, teaching, cultural strategies

Cultural strategies have long been a heated topic among translation theoreticians and practitioners alike. As early as two hundred years back, the German philosopher and translator Schleiermacher puts forth two methods for translators: Either the translator leaves the author in peace, as much as possible, and moves the reader toward him, or he leaves the reader in peace, as much as possible, and moves the author toward him (Lefevere 1992: 149). Of which he favors the latter. In this vein, the deconstructionist Venuti differentiates two strategies in translation: domesticating and foreignizing. He strongly advocates the resistant foreignizing method and rejects the transparent domestication in opposition to the Anglo-American hegemonic cultural stand (Venuti
1995: 20). While to the cultural school scholars, translators should bring into being an entirely different register which tends to match as closely as possible the dominant poetics in the target language, and translations can manipulate text structure and texture, thus, translators are seen to be faithful when the target

aThe College of Post and Telecommunication of WIT, Wuhan, China

bHuazhong University of Science and Technology, Wuhan, China

\section{Correspondent Author:}

Shu-huai Wang, School of Foreign Languages, Huazhong University of Science and Technology, Wuhan, China, Postcode 430074

E-mail: wangshh@hust.edu.cn 
text functions in particular ways and target readership finds it more acceptable (Hatim 2001: 208-213). So they are completely target-oriented, the literary, linguistic, and cultural values of the target language are of top importance in the translators' strategic design.

In China, the twentieth century saw Lu Xun's upholding of foreignization by a demand of "keep exotic flavors", and Fu Lei and Qian Zhongshu's upholding of domestication by respective appeal for "pursuit of spiritual rather than formal resemblance" and "sublimation", and domestication seemed to be dominant in that century. The beginning of this century also has witnessed a hot debate over the time-honored question: Sun Zhili (2002) predicts that foreignizaton will be the trend in translations following up, while Cai Ping (2002) claims that domestication must be the main strategy in translation, and Guo Jianzhong (2000) proposes an eclectic way to make choices based upon author intention, text type, translation purpose, and audience design. However, on a wide range, foreignization seems to be gaining the upper hand as the century unfolds itself.

\section{THE DISCREPANCY OF CULTURAL STRATEGIES BETWEEN ORDINARY TRANSLATION THEORIES AND TRANSLATION TEACHING}

Translation teachers should realize the revelations from deconstructionist, cultural school, and skopos theories. Facing a dominant English culture, it is sensible to take a cultural stance neither self-assuming nor self-abased. On the one hand, the deconstructionist foreignization enables transmitting heterogeneity to other cultures, thus promoting Chinese culture abroad, which satisfies the requirement of the increasing globalization; on the other hand, to guarantee translation acceptance and survival, translators have to adapt in some measure to the linguistic, literary, and cultural values of the English speaking community.
Also, this is where translation teaching should strike a balance in between.

There are a lot of differences between translation teaching and ordinary translation theories. First, ordinary theories tend to be active and dynamic, originality from the previous research paradigms is the essence of advancement. Yet for translation teaching, the theories always seek the practical value: to improve students' basic practical abilities and refine their text conversion competence. Second, with a view to highlighting translators' "presence", deconstructionist approach claims "abusive fidelity" (Lewis 1985: 41) and objects to logos in the source text, while linguistic competence in terms of fluency and right pursuance of text meaning are often highly stressed in translator training. Third, the deconstructionist approach advocates the resistant method instead of transparent language, but in novices C-E (Chinese-English) training, this may play down their awareness of English, and even kill their initial inclination toward idiomaticness, which will inevitably lead to English speakers' refusal of the learners' translation, either literary or technical. Finally, over catering to English community's culture-dominating minds and willful changes of the original will dilapidate the trainee's translation norms and culture evaluation ability.

The two cultural poles in ordinary translation theories-domestication and foreignization are somewhat general and sometimes even misleading in translation teaching. Luo Xuanmin (2004) suggests that culture could be studied from two levels: Linguistically, when translation is aimed at art, the two opposing strategies are assimilation and alienation; culturally, when translation is aimed at ideology, the two contrary strategies are domesticating (colonializing) and foreignizing (decolonializing). This makes the issue much clearer. However, in undergraduate translation teaching, student translators's ability should be focused on cultural image conversion rather than political agenda, culturally their strategies should be otherwise shifted. 
Again, students should be led to investigate culture from the two strata: linguistic and cultural. On linguistic stratum, the two extremes - assimilation and alienation should be clearly differentiated. By assimilation, the translator dissolves source lexical forms, syntactic structures, and text patterns into the target mould, in C-E translation, the translated language has all the genuine features of English; by alienation, the translator heavily stuffs his target text with source language characteristics, including rhetorical devices and syntactic and generic structures with different degrees of acceptability, in which case the C-E translation is likely to be rife with interlanguage. On cultural stratum, there are also two extreme approaches: adaptation and exoticization. Adaptation means the translator interprets the source culture in terms of the target correspondent, using cultural equivalents or modifications so that the reader's sense of foreignness may be alleviated and his/her desire of ethnocentrism is satisfied; by exoticization, the translator faithfully introduces the heterogeneous elements into the target language, using amplification, annotation, etc., so that the reader may have a true picture of the original and she/he may even appreciate the ethnodeviant values.

\section{THE CONFIGURATION OF STUDENTS' CULTURAL COMPETENCE}

Cultural competence is the ability to perceive the cultural other, to differentiate the cultural other from self, to give them objective evaluations, and to coordinate the different sides. It is the foundation of wieldy handling of translation strategies, and an incomplete structure which may result in failing strategies. It is mainly composed of four parts:

(1) Culture perceptive ability. It requires in C-E translation, the students' awareness of what is unique of Chinese culture, and the degrees it deviates from the English counterpart. Just as Nord (1997: 79) observes, in order to understand the specificity of another culture, you have to know your own culture first;

(2) Culture comparison ability. It requires that students should be clear about the overlapping and divergence of the two cultures: in what respects they resemble and in what other respects they differ;

(3) Culture evaluation ability. It demands that the students should be capable of appraising the values and potentials of the two cultures, even historicizing them, i.e., evaluating them against a historical background. In the present context, teachers should let their students realize that compared with English culture, Chinese culture is less dominating or weak positioned according to Wang Hong-yin's three criteria for comparing cultural encountering: historical heritage, overall power, and psychological identity (Wang 2004);

(4) Culture mediation ability. It entails student translators' ability to avoid crushing head-on conflicts on the two cultures' cognitive and affectional modes, successfully converse cultural images, and transmit the exotic and acceptable elements as many as possible. Thus, while conducting the weak positioned Chinese culture into English, they must master the skills to bridge cultural abysses, such as amplification, annotation, thick glosses, cultural equivalents, modification, or even deletion and rewriting.

\section{CULTURAL STRATEGIES FOR UNDERGRADUATE C-E TRANSLATION TEACHING}

As the authors discussed above, the beginning of this century finds a good number of Chinese theoreticians in favor of the foreignizing strategy. In translation teaching, teachers cannot simply follow suit. We should probe into the canonical translations, which are very popular among native speakers, e.g., The Story of the Stone translated by David Hawkes, Six Chapters of a Floating Life by Lin Yu-tang, and Strange Tales From Make-do Studio by the Mares. Their cultural 
strategies are quite revealing to learners. The authors' observations show that they employ different methods at different levels. Usually, culture is believed to comprise three levels: the surface level of material culture (MC), the middle level of institutional culture (IC), and the inside level of spiritual culture (SC). MC includes clothes, food, color, wares, environment, etc.; IC includes regulation, custom, organization, politeness system, nonverbal language, etc.; SC includes cognitive and affectional mode, world outlook, religious affiliation, sex attitude, etc. The inspiration of great translators' strategies at different cultural levels will be dealt with later.

\section{Linguistic Training Strategies}

In terms of language that interconnects the three levels of culture, the canonical C-E translations all use idiomatic and genuine English. This is also demanded of the students: Their language strategy is adaptation rather than alienation. Linguistic training strategies can be carried out at four levels:

(1) Lexical level. Students are required to choose their words in terms of accurate conceptual meaning, connotative meaning, stylistic meaning, and vivid rhetorical meaning;

(2) Grammatical level. Students' translation must be free of grammatical mistakes and, further, they should be able to alternate the length and complexity of sentences, and have a good command of prepositional phrases, non-finite forms, and independent structures so as to make the syntactic structures genuine, concise, and varied;

(3) Textual and pragmatic level. Students should be aware of linguistic cohesion, conceptual coherence, and thematic progression in order to achieve the overall textual purpose. And they should know how to arrange both micro and macro structures according to English text norm in line with text type and text function;

(4) Aesthetic level. Students should make their translation concise and structurally complete, stylistically appropriate, and produce a good contrast of deviation and norm, e.g., lexical deviations of illogicality, unreliability, and "redundant" encoding (Shen 1995: 103-162), so as to achieve the permeating effect of figurative images and touching emotions.

As these may involve too many aspects, the teaching ideology has to be structuralism (Bruner 1960), the curricula are designed in structured patterns, and developed higher in spirals and reflection. Herein the idea will not be unfolded for limitation of space.

\section{Cultural Strategies}

Cultural strategies in translation of practical material. The material for undergraduates C-E translation training should encompass literary and practical components, as literary translation aims to lay a solid linguistic foundation for the students and add to their aesthetic reproductive ability, while practical translation, including scientific, technical, advertisement, profile, and legal translations, etc., aims to equip students with some base knowledge of specific genres and basic translation skills that will facilitate their future work. Comparatively, practical translation contains much fewer cultural points, however, students still have some cultural bogs to cover. It is functionality that determines the cultural strategy. If the element to be translated is against functionality, adaptation should be employed; if it conforms to functionality, then exoticization should be employed.

And what are the criteria of functionality?

(1) Generic structure. Generic structure is the conventionalized form of a specific text composition relating to a special social occasion, it is often different in cross-cultural communication. To take an example of company profile translation, the Chinese version is often structurally an unsegmented whole, with different themes mingled together. To render this into English, students should learn to rearrange it into several parts each with a clear and centered theme and topic, e.g., history and splendor, spirit and culture, 
achievements and awards, business scope, contact, etc.;

(2) Cognitive mode. This is the expression of value system latent in the recesses of people's minds, it is about people's conceptualization and attitude toward self and the world. For example, one Chinese company may claim in its advertisement: "Our company is state-run", "Our manager is so and so", "Our guiding principle is high respect for credit and splendid contract execution", "The state leader so and so has visited our company and profusely praised our product"... All these lines contravene English advertisement value system: English-speaking people are solicitous about trademark, product quality, specifications and prices, consumer benefits, novelty of experience or service, and mostly they are apolitical. So the Chinese version of the advertisement has to be rearranged and adapted to the target cognitive mode;

(3) Affectional mode. Chinese people are usually emotionally milder and less direct compared with Westerners. In translation, student translators can render the emotions stronger and more explicit; in some raw materials, the author-reader distance is very big, this can be shortened in translation. Besides, words with emotional loadings may not overlap and sometimes even contradict each other across cultures. For example, the brand Huanghelou is better translated as "Yellow Stork Tower" than "Yellow Crane Tower", as "crane" suggests a dirty and ugly bird in English, although he (crane) is a symbol of longevity in Chinese culture. But "stork" in English has a positive meaning: a harbinger of good luck.

The three criteria fulfill the three meta functions of language (Halliday 1985): generic structure, textual function; cognitive mode, ideational function; affectional mode, interpersonal function.

Cultural strategies in literary translation. Referring to the experience from the canonical translations, we can subsume cultural factors under two categories: culture as the topic of writing and culture as the background of writing.
In case of culture as topic of writing, namely, when cultural element is the focus to be introduced to another culture, as for MC, i.e., clothes, food, color, wares, and environment, trainee translators should use exoticization, if there is a cultural zero, they can employ techniques of amplification, annotation, or glosses. As for IC, the most part-regulation, custom, organization, and nonverbal language should be faithfully transmitted, while some elements of politeness system, for example, honorifics, which is highly frequent in Chinese should be turned into ordinary forms in English. As for SC, the most part—world outlook, religious affiliation, and sex attitude should be loyally imparted, while some elements of cognitive and affectional mode, when contradicting their English counterparts, should be modified. This typically finds expressions in the following two aspects:

(1) Abstract-concrete conversion. This results from incommensurability in both thought patterns and language expressions. On the one hand, Chinese people recognize the world in a fuzzy, holistic, and even mysterious manner, while English-speaking people in a clear, analytic, and empiricist way; on the other hand, in some cases, Chinese being non-reflected and formally simple, pursues plain denoting, vivid imaging, and picturesque thinking, yet English, being reflected and formally involved, is general evasive and bleary. These self-contradicting points are characteristic of both English and Chinese, yet the points on question do not usually coincide in the same place. Thus, student translators should be taught to turn abstract into concrete and concrete into abstract so as to put the meaning across. For example:

Zhijian zhe nühaizi meicuchunshan, yanpinqiushui, mianboyaoxian,

He saw the girl's brow knit spring mountain, eyes press autumn water, with a thin face and waist,

niaoniaotingting, dayou Lin Dai-yu zhitai. (Cao 1987: 227)

curvaceous and soft, very much like the semblance of Lin Daiyu. 
In this case, meicuchunshan (brow knit spring mountain) and yanpinqiushui (eyes press autumn water) are the abstract and poetic Chinese ways to conceptualize and depict beautiful women. They have to be turned into concreteness, or they will end with a communication break down:

He looked more closely and, to his surprise, the girl had a natural frown that knitted her brows and saddened her eyes, with a delicate skin and a pretty waist, carrying herself in a graceful poise. In short, she was in every aspect as serene and elegant in bearing as Lin Daiyu. (Liu 2002: 433)

(2) Description affection model. In Chinese, as people tend to hold the oneness of man and nature, in their scenic or figure description, they often combine it with their own emotions. While in English, people stress the objective description of things they see, they usually separate personal feelings from descriptions. In Six Chapters of a Floating Life, Lin Yutang always omits the authorial affections mingled with the landscape descriptions.

Now let us turn to the case of culture as background of writing, i.e., cultural factors are subsidiaries to the theme.

In principle, cultural elements used in background should be literally transmitted. However, if they contravene the following two qualities, translation strategy will be adaptation instead of exoticization.

(1) The target text's aestheticality. The translated text must be an aesthetically independent entity, it should be concise and, as a self-containing gestalt, it must be harmonious, economical, and logical. Also, if it is required by rhymes, rhythms, or abstract-concrete conversion, the background cultural factors, when failing to satisfy these requirements, should undergo modification, deletion, or total alteration. For example:

\footnotetext{
Jiamu jianwuren, fangshuodao: "wo tingjian ni ti laoye shuomei laile,

Seeing there was no one beside Lady Xing, Grandmother Jia said: "I've heard you come here to make a match for your husband,
}

\begin{abstract}
ni daoyeshi sancongside, zhishi zhe xianhui ye taiguofenle!". (Cao 1987: 354)

You really have the three obediences - obey your father before marriage, your husband when married, and your son in the possible widowhood - and the four virtues - morality, proper speech, modest manner, and diligent work, but that's gone a little too far!"
\end{abstract}

We see that exhausted transmission of sancongside (three obediences and four virtues) wholly damages text gestalt: verbose, unbalanced, and inharmonious. This could be treated in a more generalized way:

When she saw that she and Lady Xing were along together, Grandmother Jia at last broke her silence: "I hear you have been playing the matchmaker for your husband", she said. "I must congratulate you on your wifely virtues - though I must say, I think that in this case you are carrying wifeliness a little far". (Hawkes 1977: 428)

(2) The target readership intertextuality. Intertextuality can be properly used, not only present the readership certain degrees of familiarity and thus geniality, but also arouse their imagination and conduct their affection to the intended direction. Contratextuality should be carefully guarded against (Hatim and Mason 1990: 131). For example:

shengyan bisan. (Cao 1987: 89)

A substantial banquet will disperse.

In China, banquets are often held to celebrate important occasions, they are suggestive of heatedness and climax. While for English people, the same functional institution is a party. To arouse English readers' equal feeling and imagination, Hawkes puts it: Even the best party must have an end (Hawkes 1973: 257).

\section{CONCLUSIONS}

In dealing with cultural factors, trainee translator should be taught to reach a balance between 
Table 1. Cultural Strategies

\begin{tabular}{|c|c|c|c|c|c|}
\hline & \multirow{2}{*}{\multicolumn{2}{|c|}{\begin{tabular}{|l|} 
Pragmatic translation \\
(material to be translated) \\
\end{tabular}}} & \multicolumn{3}{|l|}{ Literary translation } \\
\hline & & & \multirow[b]{2}{*}{ Culture in topic } & \multicolumn{2}{|c|}{ Culture in background } \\
\hline & With functionality & $\begin{array}{l}\text { Against } \\
\text { functionality }\end{array}$ & & $\begin{array}{l}\text { With } \\
\text { aesthecality/ } \\
\text { intertextuality }\end{array}$ & \begin{tabular}{|l|} 
Against \\
aesthecality/ \\
intertextuality
\end{tabular} \\
\hline MC & Exoticization & Adaptation & Exoticization & Exoticization & Adaptation \\
\hline IC & Exoticization & Adaptation & $\begin{array}{l}\text { Exoticization except part of politeness } \\
\text { system }\end{array}$ & Exoticization & Adaptation \\
\hline $\mathrm{SC}$ & Exoticization & Adaptation & $\begin{array}{l}\text { Exoticization except part of vague } \\
\text { concrete conversion/description } \\
\text { affection model }\end{array}$ & Exoticization & Adaptation \\
\hline
\end{tabular}

introducing Chinese culture outside and making the translation acceptable and enjoyable. Thus, he/she must take into consideration cultural encountering, translator's task, text type, text aestheticality, and readership intertextuality. Before drawing this paper to an end, the authors would summarize cultural strategies for undergraduate C-E translation teaching in the above table (see Table 1).

\section{Funding}

This research is supported by Huazhong University of Science and Technology's Fund for Teaching Research (Grant Number 14039).

\section{References}

Bruner, J. 1960. The Process of Education. Cambridge, M.A.: Harvard University Press.

Cai, P. 2002. "Domestication Should Be the Main Strategy in Literary Translation." Chinese Translators Journal 5:39-41.

Cao, X. Q. 1987. Hongloumeng. Changsha: Yuelu Publishing House.

Guo, J. Z. 2000. “A Cultural Approach to Translation.” Pp. 271-285 in Culture and Translation, edited by J. Guo. Beijing: Chinese Overseas Translation Corporation.

Halliday, M. A. K. 1985. An Introduction to Functional Grammar. London: Edward Arnold.

Hatim, B. 2001. Teaching and Researching Translation. England: Pearson Education Limited.

Hatim, B. and I. Mason. 1990. Discourse and the Translator.
London and New York: Longman.

Hawkes, D. 1973. The Story of the Stone. England: Penguin Books.

- 1977. The Story of the Stone. England: Penguin Books.

Lefevere, A. 1992. Translation/History/Culture. London and New York: Routledge.

Lewis, P. 1985. "The Measure of Translaiton Effects." In Difference in Translation, edited by J. Gradham. Ithaca and London: Cornell University Press.

Liu, S. C. 2002. C-E/E-C Translation and Appreciation of Choice Essays. Nanjing: Yilin Publishing House.

Luo, X. M. 2004. "On Foreignizing/Domesticating Translation on Cultural/Linguistic Level." Foreign Language Research 1:102-106.

Nord, C. 1997. Translation as a Purposeful Activity: Functional Approaches Explained. Manchester: St Jerome.

Shen, D. 1995. Literary Stylistics and Fictional Translation. Beijing: Peking University Press.

Sun, Z. L. 2002. "Literary Translation in China: From Domestication to Foreignization." Chinese Translators Journal 1:40-44.

Venuti, L. 1995. The Translator's Invisibility: A History of Translation. London and New York: Routledge.

Wang, H. Y. 2004. "On Background Variables of Translation Criticism in Literature.” Chinese Translators Journal 2:36-39.

\section{Bios}

Chunying Li, MA, lecturer, the College of Post and Telecommunication of WIT, Wuhan, Hubei, China; research fields: translation and English teaching.

Shu-huai Wang, Ph.D., professor, Huazhong University of Science and Technology, China; research fields: translation teaching and translation criticism. 